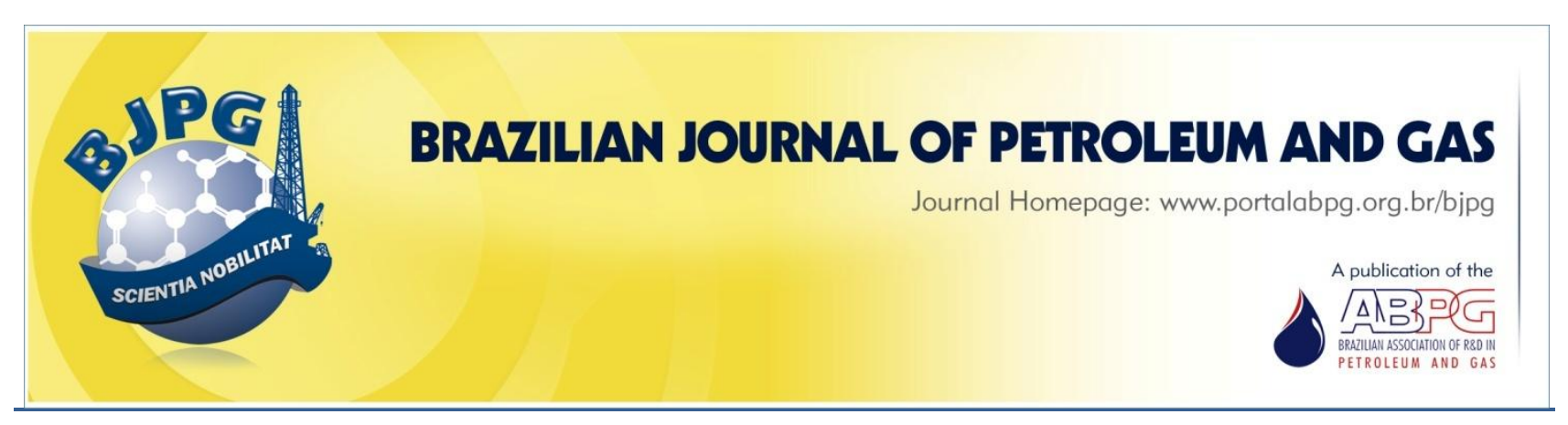

\title{
SYNERGISM STUDY OF MIXTURES OF IONIC AND NONIONIC SURFACTANTS IN ENHANCED OIL RECOVERY ADSORPTION
}

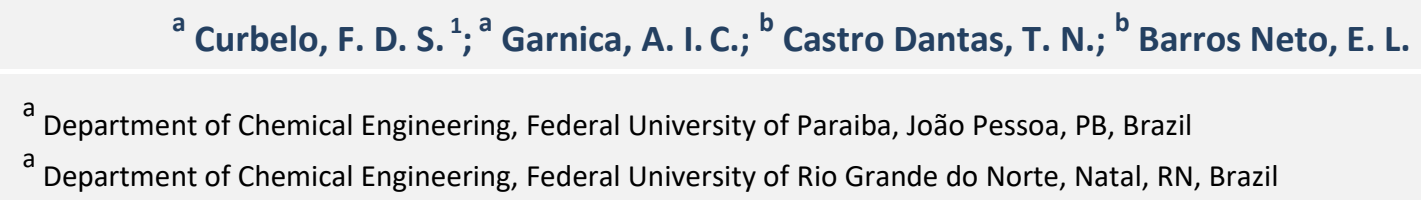

Received: 26.02.2017 / Revised: 23.06.2017 / Accepted: 30.06.2017 / Published on line: 18.07.2017

\begin{abstract}
Adsorption of surfactants from aqueous solutions in porous media is fundamental in enhanced oil recovery (EOR) because surfactant loss reduces the effectiveness of the chemical solution injected, making the process economically unfeasible. This paper analyzes surfactants' synergistic effects in adsorption and enhanced oil recovery. This study used nonionic (nonylphenol 20 ethylene oxide - R200) and anionic surfactants (saponified coconut oil - OCS and base soap - SB) with the two mixtures studied (R200/OCS and R200/SB). The mixture R200/SB, due to its higher viscosity because of the presence of SB, saturated the ionic surfactant (SB) faster, reaching a higher oil recovery (70.0\%). The addition of SB surfactant in the R200 solution led to an increase in oil recovery $(70.0 \%)$ when compared to R200 alone $(64.5 \%)$.
\end{abstract}

\section{KEYWORDS}

surfactant; synergism; adsorption; critical micelle concentration; enhanced oil recovery

\footnotetext{
${ }^{1}$ To whom all correspondence should be addressed.

Address: Department of Chemical Engineering, Federal University of Paraiba, João Pessoa, PB, Brazil.

ZIP Code: 58051-900 | Cell phone: 5583 99613-8786 |e-mail: fabioladias@yahoo.com

doi:10.5419/bjpg2017-0008
} 


\section{INTRODUCTION}

Surfactant adsorption on solid surfaces may result in concentration loss and reduction, also decreasing the efficiency in practical applications of enhanced oil recovery (EOR) techniques. Surfactants are used largely in industrial processes due to their extreme ability to reduce oil-water interfacial tension (IFT). Therefore, surfactants are very important materials in chemical flooding for EOR methods. (Bera et al., 2011; 2014). Adsorption of surfactants from aqueous solutions in porous media is fundamental in EOR from oil reservoirs because surfactant loss for adsorption reduces the effectiveness of the chemical solution injected making the process economically unfeasible (Yekeen et. al., 2017; Arabloo et al., 2016; Budhathoki et. al., 2016).

Surfactants can interact to form micelles in solutions and hemimicelles at interfaces, and these aggregation phenomena can have remarkable effects on many industrial processes (Zhou \& Somasundaran, 2009). The adsorption of surfactant mixtures has been studied due to theoretical and practical interests (Huang et al., 1996; Schramm, 2000; Somasundaran \& Krishnakumar, 1997; Somasundaran \& Huang, 2000).

In this paper, synergistic tests during adsorption and enhanced oil recovery, with ionic and nonionic surfactants, were studied with the goal of obtaining a higher oil recovery than that obtained with either surfactant alone.

\section{MATERIALS AND METHODS}

\subsection{Oil sample}

A mixture of oil and kerosene, at a ratio of 2:3, respectively, was used as oil phase. This solution presented a viscosity of $2.9 \mathrm{cP}$ and specific gravity $1.13 \mathrm{~g} \mathrm{~cm}^{-3}$, at $25^{\circ} \mathrm{C}$. The oil used, crude oil without emulsifier, was supplied by Petrobras (Guamaré Oil Pole - Brazil) and collected at the Ubarana oil field.

\subsection{Brine solution}

A 2.0 wt\% potassium chloride $(\mathrm{KCl})$ solution was used as aqueous phase (brine). The $\mathrm{pH}$, viscosity, and specific gravity were $5.58,1 \mathrm{cP}$ and $1.03 \mathrm{~g} \mathrm{~cm}^{-3}$, respectively, at $25^{\circ} \mathrm{C}$.

\subsection{Surfactant solutions}

Three surfactants, a non-ionic, nonylphenol 20 ethylene oxide, designed R200, and two ionic (anionic), saponified coconut oil (OCS) and base soap (SB), were studied. The nonionic surfactant was acquired by Oxiteno (Brazil). The ethoxylation degree indicates the number of ethylene oxides present on the surfactant molecule. Surfactant solutions were prepared by dissolving the required amounts of surfactants in distilled water.

\subsection{Determination of the properties of surfactant solutions}

A specific property of surfactant solutions, considered separately or in mixtures, is the concentration above of which the first aggregates of monomers, named micelles, are formed (Minssieux, 1989). Above this concentration, called critical micelle concentration (c.m.c.), the surfactant solutions display particular solubilizing properties used in many applications (Babadagli, 2003; Yekeen et. al., 2017).

Suface tensions of the surfactant solutions at different concentrations were determined at $25^{\circ} \mathrm{C}$ using a bubble tensiometer (SensaDyne QC-6000, SensaDyne Instrument Div.). The break in the plots of In $C$ versus surface tension corresponds to the critical micelle concentration (c.m.c.) value.

\subsection{Adsorbent}

The solid adsorbent was a sample of sandstone (Açu Formation, Rio Grande do Norte - Brazil), similar to the ones observed in petroleum formations. The cores used (Figure 1) were coated with resin and had the following dimensions: 3.8 $\mathrm{cm}$ diameter, $8.7 \mathrm{~cm}$ length, and an average porosity of $24 \%$. Before coating with resin, all cores were calcined at $700{ }^{\circ} \mathrm{C}$ during 18 hours, to remove humidity, organic materials, and increase permeability. Two fluid distributors were attached in the core plug. These were covered with two core ends connected with the injection and production line, respectively. Core plug, distributors, and core ends were joined with a coating of resin.

\subsection{Oil recovery tests}

Oil recovery tests were performed by 


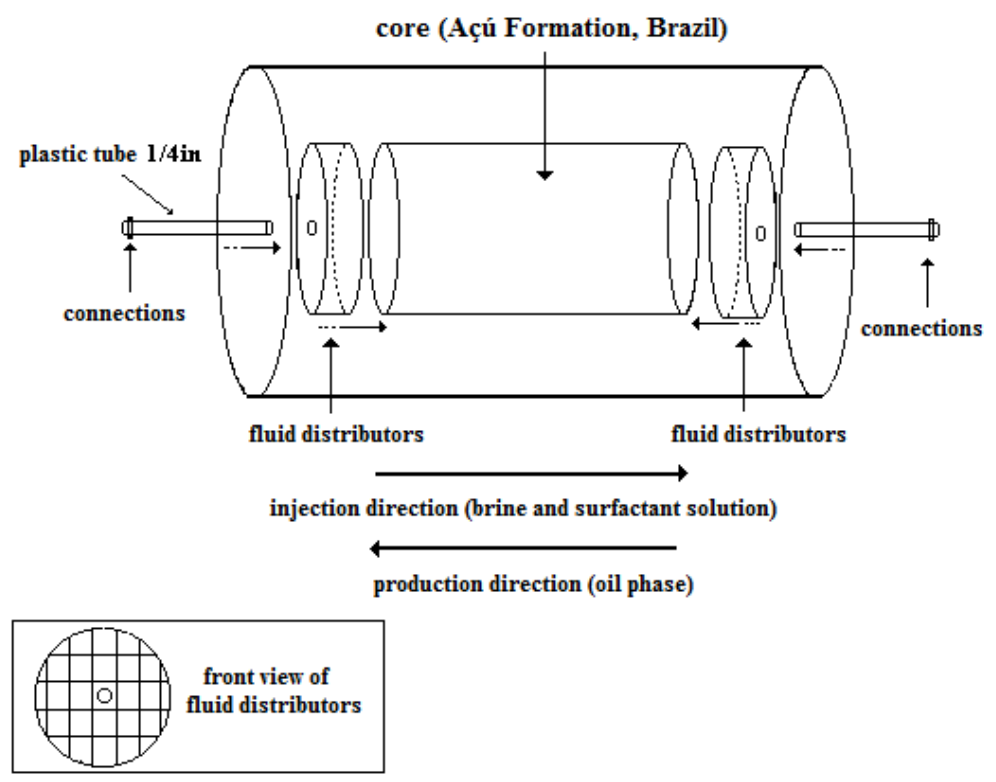

Figure 1. Preparation of sandstone cores for brine and oil recovery experiments.

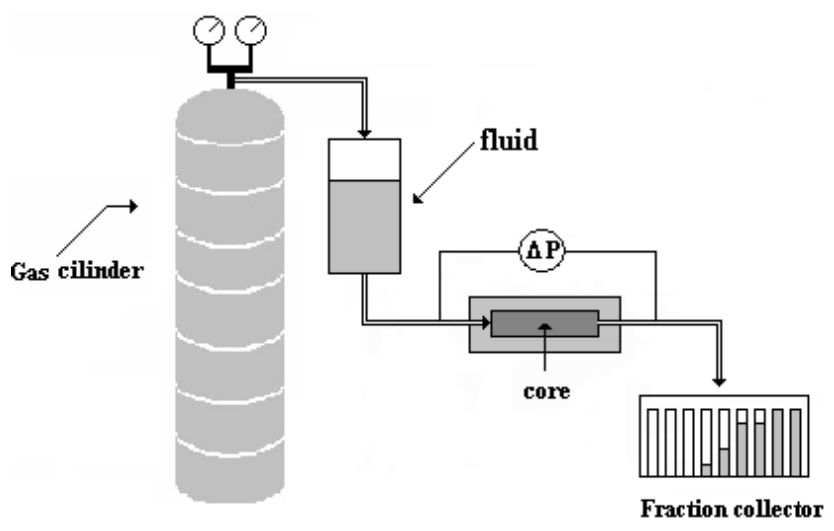

Figure 2. Experimental apparatus.

displacement of fluids in porous media. The system used in adsorption and oil recovery experiments is shown in Figure 2. Before each experiment, the core was evacuated with a vacuum pump, and the pore volume was determined by $\mathrm{N}_{2}$ injection to determine the porosity. Oil recovery tests followed the steps:

(1) Injection of brine (30 psi) until core saturation, in the opposite direction of oil production. The injection directions can be seen in Figure 1. Brine volume used was determined for mass balance;

(2) Injection of oil phase (30 psi), in the same direction of oil production. The core was flooded with oil phase until no brine was produced (irreducible water saturation). Oil volume remaining in core, called original oil in place (OOIP), was determined for mass balance;

(3) Injection of brine (30 psi), in opposite direction of oil production, corresponding to conventional oil recovery (CM). In this step, a small amount of oil is recovered, leaving greater amounts retained in porous medium due high interfacial tensions. This trapped oil is called residual oil (RO);

(4) After the three steps mentioned above, when core was saturated with brine and oil phases, injection of surfactant solution was initiated, corresponding to the enhanced oil recovery (EOR). This step aimed to recover RO (residual oil) trapped in the porous media by the reduction of interfacial tensions. 
Table 1. Values of c.m.c. for the used mixtures of surfactants.

\begin{tabular}{cccc}
\hline Mixture: R200/OCS & c.m.c. $(\mathrm{g} / \mathrm{mL})$ & Mixture: $\mathrm{R200} / \mathrm{SB}$ & c.m.c. $(\mathrm{g} / \mathrm{mL})$ \\
\hline $\mathbf{1 . 0 : 2 . 0}$ & $\mathbf{0 . 0 0 1 7}$ & $\mathbf{1 . 0 : 2 . 0}$ & $\mathbf{0 . 0 0 1 3}$ \\
$1.0: 1.0$ & 0.0015 & $1.0: 1.0$ & 0.0033 \\
$2.0: 1.0$ & 0.0041 & $2.0: 1.0$ & 0.0025 \\
\hline
\end{tabular}

Table 2. Oil recovery factor for mixtures: R200/OCS and R200/SB.

\begin{tabular}{cc}
\hline Mixture of surfactants & $\mathrm{RF}_{\text {total }}(\%)$ \\
\hline $\mathrm{R} 200 / \mathrm{OCS}$ & 46.0 \\
$\mathrm{R} 200 / \mathrm{SB}$ & 70.0 \\
\hline
\end{tabular}

To determine the oil recovery factor (RF), two methods were used: conventional method (CM) and, subsequently, special method (EOR). The $\mathrm{RF}_{\mathrm{CM}}$ was obtained by injecting brine in the core (step 3). Residual oil volume $(\mathrm{mL})$, to be recovered by EOR method, was determined by mass balance, shown in equation (1).

Volume $_{\text {residualoil }}=$

$=$ Volume $_{\text {injected }}-$ Volume $_{\text {produced } C M}$

Recovery factor (RF) was determined by the sum of the amounts of oil recovered by conventional (CM) and special (EOR) methods, as shown in equation (2):

$$
R F_{\text {total }}=R F_{C M}+R F_{E O R}=\frac{v_{C M}+v_{E O R}}{v_{\text {total }}}
$$

Where: $\mathrm{RF}_{\text {total }}$ is the total recovery factor (\%); $\mathrm{RF}_{\mathrm{CM}}$ is the recovery factor obtained by conventional method (\%); $R F_{E O R}$ is the recovery factor obtained by special method (\%); $\mathrm{V}_{\mathrm{CM}}$ and $\mathrm{V}_{\mathrm{EOR}}$ are volume of oil recovered by conventional method $(\mathrm{mL})$ and special method $(\mathrm{mL})$, respectively; and $V_{\text {total }}$ is total volume of OOIP $(\mathrm{mL})$.

In oil recovery tests, solutions of surfactants were injected in the same core and in ascending order of concentration. If the experiments were conducted individually, highest concentrations of surfactants would have been used to recover all the oil that was achieved by lower concentrations.

\subsection{Adsorption tests}

Surfactant adsorption was determined by the single-phase injection method. Surfactant solution was injected continuously into the core until equilibrium was reached, that is, until surfactant concentration in effluent reached the injected surfactant concentration. Surfactant injection tests were carried at $25{ }^{\circ} \mathrm{C}$ with surfactant concentrations $30 \%$ above c.m.c., providing a micellar solution.

All tests were performed in the absence of residual oil in porous media, in conditions that solid surfaces were available for surfactant, corresponding to maximum adsorption.

\section{RESULTS AND DISCUSSION}

\subsection{Critical micelle concentration (c.m.c.)}

Table 1 shows the c.m.c. of the mixtures of surfactants used in adsorption and enhanced oil recovery tests.

For mixture R200/OCS, the ratio 1.0:2.0 was chosen for the tests. This ratio obtained the lowest mass of surfactant R200, which is the most expensive surfactant, and presented low values of c.m.c. $(0.0017 \mathrm{~g} / \mathrm{mL})$. To the mixture R200/SB, the ratio 1.0: 2.0 was used for tests, due to the lower value of c.m.c. (0.0013 g/mL), consuming, thus, less surfactant.

\subsection{0il recovery}

The concentrations of surfactant mixtures injected ranged from $30 \%$ to $50 \%$ above the c.m.c. Recovery factors ( $\left.\mathrm{RF}_{\text {total }}\right)$ are shown in Table 2.

Studies performed by Curbelo et al. (2007; 2008) show that solutions of surfactants R200, SB, and OCS injected, individually, had recovery factors 


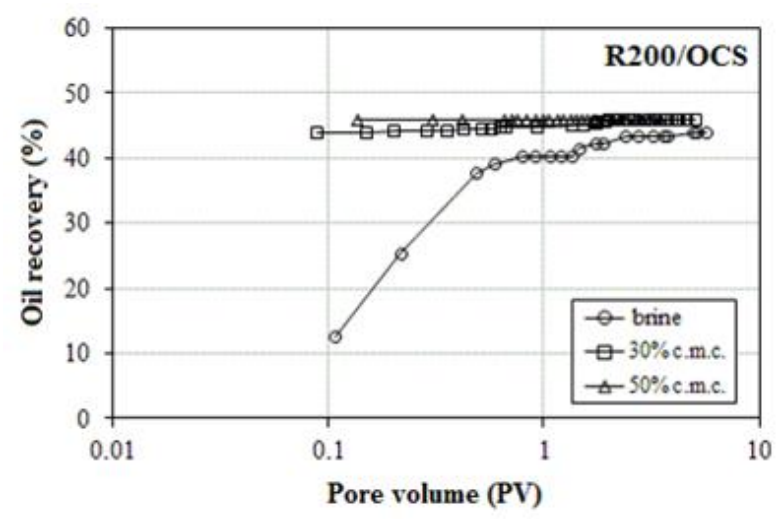

(a)

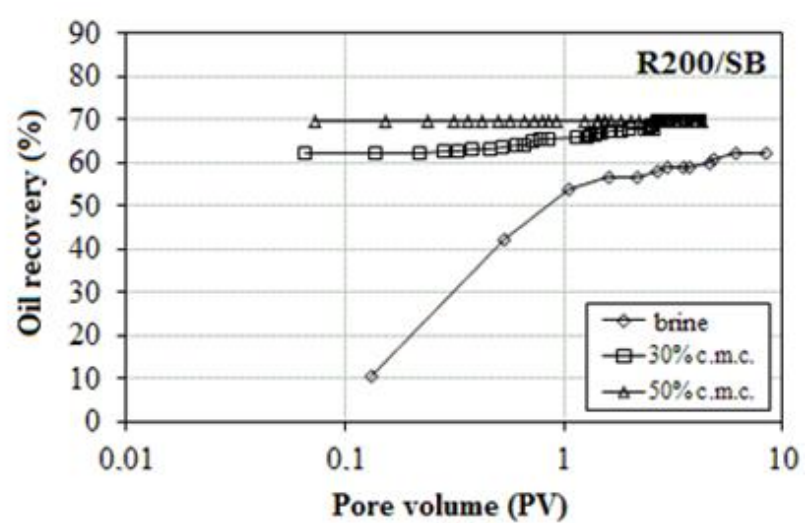

(b)

Figure 3. Recovery factor for surfactant mixtures R200/OCS (a) and R200/SB (b).

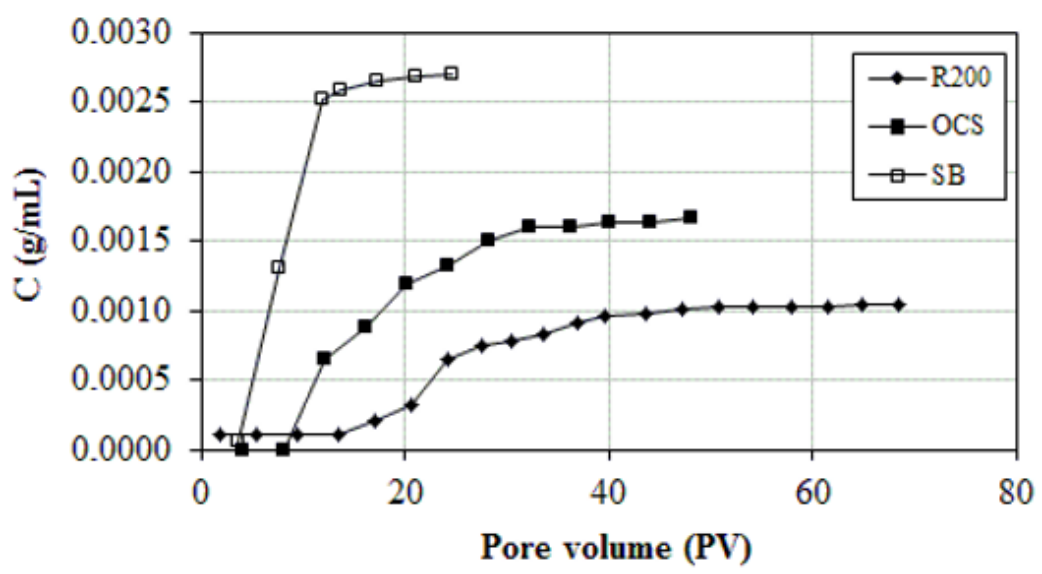

Figure 4. Adsorption of surfactants R200, OCS, and SB on sandstone cores.

$\left(\mathrm{RF}_{\text {total }}\right)$ of $64.5 \%, 78.0 \%$, and $89.0 \%$, respectively. From table 2, one can observe that synergism to R200/OCS mixture was not satisfactory because the recovery factor decreased to $46.0 \%$ (Figure 3.a). However, for synergism to R200/SB mixture, recovery factor increased to $70.0 \%$ (Figure $3 \mathrm{~b}$ ).

Surfactant SB presented a viscosity of $3.0 \mathrm{cP}$, value close to oil viscosity $(2.9 \mathrm{cP})$. The mixture R200/SB behaved like a polymer with satisfactory mobility ratio and obtaining good sweep efficiencies, because the polymers have the ability to increase the viscosity of the injected fluid directing oil to production wells. This mixture also got good displacement efficiencies, interacting chemically with the rock, and lowering the interfacial tension between surfactant solution (injected fluid) and trapped oil (fluid displaced), important factors in the enhanced oil recovery process.

\subsection{Surfactant adsorption}

During oil recovery tests, surfactant adsorption was investigated. Figure 4 shows the adsorption of surfactants on sandstone.

It is observed in Figure 4 that, when injected individually, surfactant saturation reached maximum adsorption at $44 \mathrm{PV}$ and $0.0010 \mathrm{~g} / \mathrm{mL}$ for R200; 32 PV and $0.0016 \mathrm{~g} / \mathrm{mL}$ for OCS; and 14 PV and $0026 \mathrm{~g} / \mathrm{mL}$ for SB. The maximum adsorption for these surfactants was achieved in values close to their c.m.c., which are $0.0008 \mathrm{~g} / \mathrm{mL}, 0.0013$ $\mathrm{g} / \mathrm{mL}$, and $0.0017 \mathrm{~g} / \mathrm{mL}$ for R200, SB, and OCS, respectively.

The ionic surfactant adsorptions differ from the ones of nonionic surfactants due to absence of electrostatic interactions (Somasundaran \& Krishnakumar, 2000). As nonionic surfactants do 


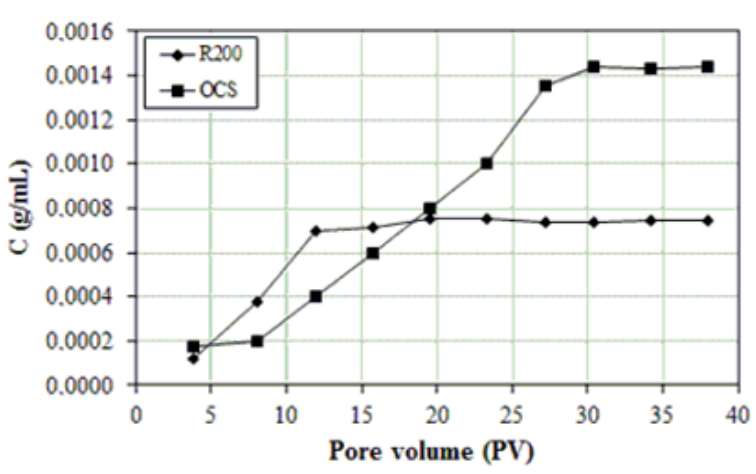

(a)

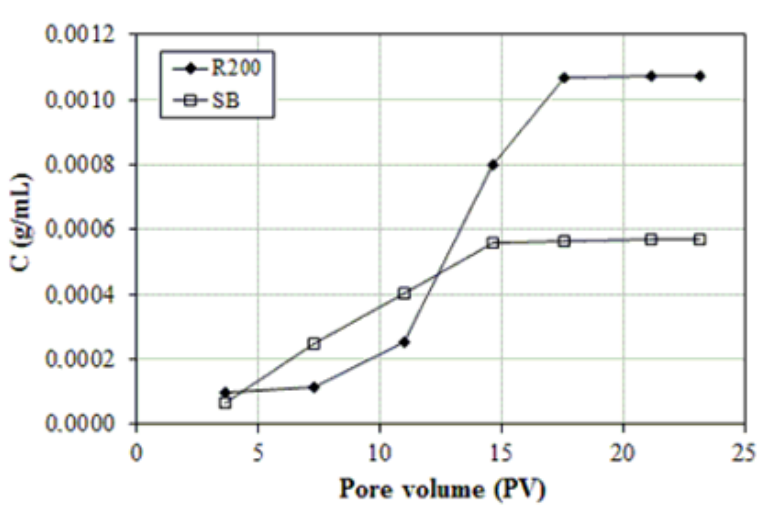

(b)

Figure 5. Adsorption during enhanced oil recovery tests for R200/OCS (a) and R200/SB (b) surfactant mixtures.

not dissociate in solution, they do not adsorb strongly with solid surface. As it can be observed, when compared with OCS and SB adsorption, results obtained by R200 surfactant reached the maximum adsorption in higher amounts of pore volumes injected.

Adsorption of R200/OCS and R200/SB mixtures are shown in Figures $5(\mathrm{a})$ and $(\mathrm{b})$, respectively.

For the R200/OCS mixture (Figure 5.a), R200 reached saturation after the injection of $12 \mathrm{PV}$ and $0.0007 \mathrm{~g} / \mathrm{mL}$, while OCS saturated with $30 \mathrm{PV}$ and $0.0014 \mathrm{~g} / \mathrm{mL}$, with the non-ionic saturating first. For the R200/SB mixture (Figure 5.b), R200 reached saturation after the injection of $17 \mathrm{PV}$ and 0.0011 $\mathrm{g} / \mathrm{mL}$, and SB after $15 \mathrm{PV}$ and $0.00056 \mathrm{~g} / \mathrm{mL}$, with the ionic surfactant saturating first with large amounts of SB available for recovery. The latter blend showed a greater recovery, $70.0 \%$ (Table 2).

The synergistic effect of surfactant mixtures may lead to increased adsorption of nonionic surfactants due to the presence of ionic surfactants, and vice-versa. Experiments show that ionic and nonionic surfactants, when used in mixtures, may be forced to adsorb onto substrates, even if no adsorption occurs individually.

The synergistic effect of surfactant mixtures led to a better packing of ionic surfactants, while the adsorption of nonionic surfactants was attributed to their solubility in hydrophobic microdomains formed by ionic surfactants. Due to this, the maximum adsorption of surfactants for both mixtures, R200/OCS and R200/SB, was reached slightly below the c.m.c. mixture (Table 1 ).
The reduction of the maximum adsorption of surfactants, verified in synergistic effects, was more pronounced for mixture R200/SB. R200 reached saturation at concentration of 0.0011 $\mathrm{g} / \mathrm{mL}$ and $\mathrm{SB}$ at $0.00056 \mathrm{~g} / \mathrm{mL}$ (Figure 5.b). These numbers show a significant decrease in the amount of SB adsorbed on the rock, when injected individually (Figure 4), but a slight increase in the case of R200. This synergistic effect, together with the higher oil recovery factor achieved, equals to 70.0\% (Table 2), making the process more effective. From the economic standpoint, the use of a surfactant blend is more viable because less surfactant is adsorbed onto the rock's surface.

\section{CONCLUSIONS}

This paper studied the synergistic effects during adsorption and enhanced oil recovery tests with ionic and nonionic surfactants. From the results obtained, one could observe that adsorption of surfactants mixtures at the solid-liquid interface depend on the nature of the surfactant, both for ionic and nonionic.

For the two surfactants mixtures evaluated, surfactant adsorption was below the c.m.c., showing that synergistic interactions occurred between them. The R200/SB mixture presented a higher viscosity due to the presence of $\mathrm{SB}$, reaching a higher recovery factor $(70.0 \%)$, when compared with R200 alone (64.5\%). 


\section{ACKNOWLEDGMENTS}

The authors acknowledge the Brazilian National Agency of Petroleum, Natural Gas, and Biofuels Human Resources Program 14 (ANP - PRH14) and the Department of Chemical Engineering at the Federal University of Rio Grande do Norte, Brazil, for the financial support.

\section{REFERENCES}

Arabloo, M.; Ghazanfari, M. H.; Rashtchian, D. Wettability modification, interfacial tension and adsorption characteristics of a new surfactant: Implications for enhanced oil recovery. Fuel, v. 185, p. 199-210, 2016. https://doi.org/10.1016/i.fuel.2016.06.088

Babadagli, T. Selection of proper enhanced oil recovery fluid for efficient matrix recovery in fractured oil reservoirs. Colloids and Surfaces A: Physicochemical and Engineering Aspects, v. 223, p. 157 - 175, 2003. https://doi.org/10.1016/S09277757(03)00170-5

Bera, A.; Kumar, T.; Ojha, K.; Mandal, A. Interfacial tension and phase behavior of surfactant-brine-oil system. Colloids and Surfaces A: Physicochemical and Engineering Aspects, v. 383, p. 114-119, 2011.

https://doi.org/10.1016/i.colsurfa.2011.03.035

Bera, A.; Kumar, T.; Ojha, K.; Mandal, A. Adsorption of surfactants on sand surface in enhanced oil recovery: Isotherms, kinetics and thermodynamic studies. Applied Surface Science, v. 284, p. 87-99, 2014.

https://doi.org/10.1016/i.apsusc.2013.07.029

Budhathoki, M.; Barnee, S. H. R.; Shiau, B. J.; Harwell, J. H. Improved oil recovery by reducing surfactant adsorption with polyelectrolyte in high saline brine. Colloids and Surfaces A: Physicochemical and Engineering Aspects, v. 498, p. 66-73, 2016.

https://doi.org/10.1016/j.colsurfa.2016.03.012

Curbelo, F. D. S.; Santanna, V. C.; Barros Neto. E. L.; Dutra Junior, T. V.; Castro Dantas, T. N.; Dantas Neto, A. A.; Garnica, A. I. C. Adsorption of nonionic surfactants in sandstone. Colloids and Surface A: Physicochem. Eng. Aspects, v. 293, p. 1-4, 2007. https://doi.org/10.1016/j.colsurfa.2006.06.038
Curbelo, F. D. S.; Barros Neto, E. L.; Dutra Junior, T. V.; Castro Dantas, T. N.; Garnica, A. I. C. Oil recovery performance of surfactant solutions and adsorption in sandstone. Petroleum Science and Technology, v. 26, p. 77-90, 2008.

https://doi.org/10.1080/10916460600705790

Huang, L.; Maltesh, C.; Somasundaran, P. Adsorption Behavior of Cationic and Nonionic Surfactant Mixtures at the Alumina-Water Interface. Journal of Colloid and Interface Science, v. 177, p. 222-228, 1996.

https://doi.org/10.1006/jcis.1996.0024

Minssieux, L. Method for adsorption reduction of mixed surfactant systems. Journal of Petroleum Science and Engineering, v. 2, p. $235-244,1989$. https://doi.org/10.1016/0920-4105(89)90069-7

Schramm, L.L. Surfactants: Fundamentals and Applications in the Petroleum Industry. Cambridge: Cambridge University Press, UK, 665 pages, 2000.

https://doi.org/10.1017/CBO9780511524844

Somasundaran, P.; Huang, L. Adsorption/ aggregation of surfactants and their mixtures at solid-liquid interfaces. Advances in Colloid and Interface Science, v. 88, p. 179-208, 2000. https://doi.org/10.1016/50001-8686(00)00044-0

Somasundaran, P; Krishnakumar, S. Adsorption of surfactants and polymers at the solid-liquid interface. Colloids and Surfaces A: Physicochemical and Engineering Aspects, v. 123124, p. 491-513, 1997.

https://doi.org/10.1016/S0927-7757(96)03829-0

Yekeen, N; Manan, M. A.; Idris, A. K.; Samin, A. $M$. Influence of surfactant and electrolyte concentrations on surfactant Adsorption and foaming characteristics. Journal of Petroleum Science and Engineering, v. 149, p. 612-622, 2017. https://doi.org/10.1016/i.petrol.2016.11.018

Zhou, Q.; Somasundaran, P. Synergistic adsorption of mixtures of cationic gemini and nonionic sugar-based surfactant on silica. Journal of Colloid and Interface Science, v. 331, p. 288294, 2009. https://doi.org/10.1016/j.jcis.2008.11.062 